\title{
Accuracy analysis of SRTM usage for upper Citarum River flood modeling
}

\author{
Riza Inanda Siregar ${ }^{1, *}$ \\ ${ }^{1}$ Civil Engineering Department, Sumatera Utara University, 20155 Medan, Indonesia
}

\begin{abstract}
Natural channel cross section is generally very irregular and varied, for complex cross-sections and natural cross sections no specific formula presents to express the elements of the geometric cross section of the channel. The study uses HEC-Geo RAS with Arc GIS 10 and HEC-RAS 4.1.0 for modeling and 1D hydrodynamic. The surveyed cross sections modeling is calibrated and validated with observed daily discharge. Then the surveyed data cross sections are replaced by the cross sections extracted from SRTM. Accuracy is suitability between the surveyed data cross sections with data cross sections which extracted from SRTM. Accuracy is expressed by the magnitude of the error. The ratio of simulated discharges between two models by surveyed data cross sections and SRTM data cross sections have index of performance indicator for Nash-Sutcliffe Index (NI) is 0.95 and index of Root Mean Square Error (RMSE) is 0.41 . Index of Performance indicator for comparison of simulated discharges between models with Nash-Sutcliffe Index (NI) is 0.95 and index of Root Mean Square Error (RMSE) is 0.41. The results show that cross sections from SRTM can be an alternative to extract data cross sections for Upper Citarum River flood modeling.
\end{abstract}

\section{Introduction}

Natural channel sections are in general very irregular from approximate parabola to approximate trapezoid. The river which frequent floods, the channel may consist of main channel section carrying normal discharges and one side channel sections to release the overflow [1].

Hydraulic river modeling needs cross sections to geometric data analysis. In generally, river cross sections can be obtained by surveying river geometric. Geometric data such as data cross sections of river is complicated to obtain the data information, so we need an alternative to acquire data easily without field surveys. The alternative aims to get the river data cross sections that can be used in river flood modeling. The modeling is expected having results as accurate as using the surveyed river cross section [2].

In this study, there are two different sources data of river cross sections. The first river modeling uses source data of river cross sections from surveyed cross sections and the second uses alternative data. The source of alternative data uses SRTM (Shuttle Radar Topography Mission) with the resolution is 90 meters for the entire surface of the world. The SRTM is generated to release river cross sections.

DEMs are used for 2D hydrodynamic flood modeling and simulation algorithm. The data is used for predictions which are compared with published flood maps and observed flood conditions [3].

A method of approach to generate river data cross sections from the ASTER DEM with low resolution and the inadequate vertical accuracy of such as global data present differentiating features of hydraulic importance, which necessitate processing of the DEMs before use for river flood modeling [4].

1-dimensional modeling is modeling that has a oneway flow is the main flow along the flow direction. Hydraulic River modeling uses software HEC-RAS to simulate daily discharge based on source data from surveyed cross sections and generated SRTM. The model with two source data will be compared to analyze the accuracy of SRTM usage for Upper Citarum River Modeling.

\subsection{Upper Citarum River}

The Upper Citarum watershed is at West Java with a height ranging between 625-2600 meters above sea level. The Upper Citarum is geographically located at $6^{\circ} 43$ '21,8” - $7^{\circ} 19^{\prime} 38,1^{\prime \prime}$ South Latitude and 107'32'2" $107^{\circ} 53^{\prime} 51,6^{\prime}$ "East Longitude. The upstream basin is surrounded by mountains and hills.

Annual rainfall varies from an average of $1000 \mathrm{~mm}$ in the coastal areas and increases to $4000 \mathrm{~mm}$ in the mountains, at the top of the watershed [5].

Upper Citarum watershed's area is about $1771 \mathrm{~km}^{2}$. Upper Citarum River flow is affected by the thirteen tributaries. It flows through in South Bandung to the Saguling reservoir with the length 31 kilometers. The SRTM of Upper Citarum River can be seen in Figure 1.

\footnotetext{
Corresponding author: rizawaloed@yahoo.com
} 


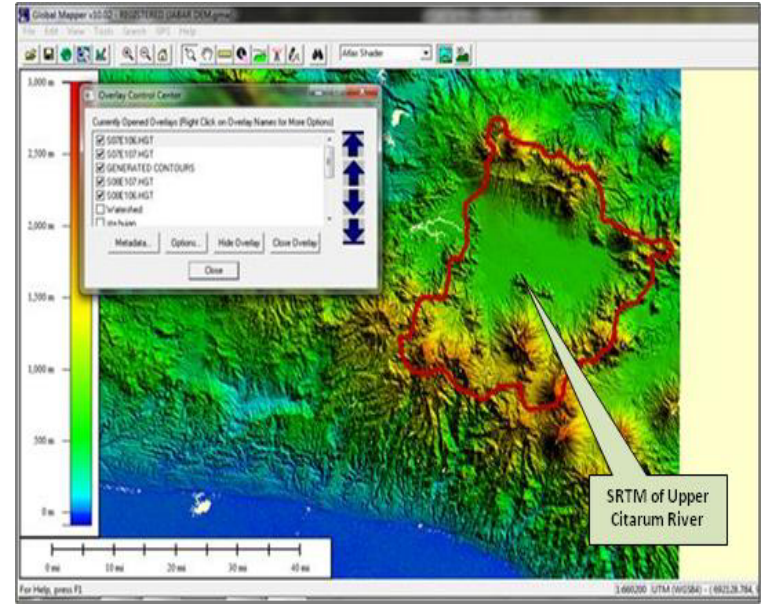

Fig.1. SRTM of Upper Citarum River and its catchment

Figure 1 shows that SRTM of Upper Citarum River and its catchment. The main purpose of the river data cross sections extracted from SRTM is to collect topographic data and makes data DEM (Digital Elevation Model). The SRTM with 90\% confidence intervals and with global coverage area has absolute horizontal and vertical accuracy better than 20 and 16 meters [6].

SRTM is a satellite image depicting the height/elevation of each grid with each grid dimensions: $90 \times 90$ meters. The imaging project SRTM led by the National Geospatial-Intelligence Agency (NGA) and the National Aeronautics and Space Administration (NASA). Both are state-owned institutions United States [7]. However, the SRTM data can be used and developed the data and for public is free.

\subsection{HEC-RAS and HEC-GEO RAS}

HEC-RAS stands Hydrologic Engineering Centre River Analysis System software is an application program for one dimensional hydraulic modeling in open channels flow. One dimensional modeling is model that has flow direction, which is the direction of flow along main flow. A hydraulic modeling will analyze hydraulic basically looking for the depth and speed of the flow along the groove which is the result of the discharge at the input as a boundary condition [8].

Unsteady flow is a physical process in the flow in a channel by adopting the concept of conservation of mass and momentum conservation. This physical process can be described by mathematical equations, known as the equation St. Venant [8]. The equations consist of continuity equation (mass conservation principle) and the momentum equation (the principle of conservation of momentum), which is written in the form of partial differential equations as follows:

The continuity equation:

$$
\frac{\partial A}{\partial t}+\frac{\partial Q}{\partial x}-q_{l}=0
$$

The momentum equation:

$$
\frac{\partial Q}{\partial t}+\frac{\partial Q V}{\partial x}+g A\left(\frac{\partial z}{\partial x}+S_{f}\right)=0
$$

Where: $\mathrm{A}=$ area (amount of flow in the main channel and overbank channel), $\mathrm{Q}=$ flow discharge, $\mathrm{ql}=$ lateral discharge per unit width of channel, $\mathrm{V}=$ velocity, $\mathrm{g}=$ acceleration of gravity, $x=$ distance which measured in flow direction to downstream, $\mathrm{z}=$ mean depth, $\mathrm{t}=$ time of flow. HEC-Geo RAS is software to process geospatial data which is set of Arc GIS tools for used with the HEC-RAS. The extension allows the users with limited GIS experience to generate HEC-RAS import file containing geometric data from an existing DMT (Digital Terrain Model) and complementary data set [9].

\section{Methodologies}

The study uses HEC-Geo RAS and Arc GIS 10 and HEC-RAS 4.1.0 for modeling 1D hydrodynamic. Daily rainfall data are from 21 stations in 2011. Then the model is calibrated and validated with observed daily discharge in Nanjung which is a discharge measurement stations. The period of calibration is January 2011 to April 2011 and period of validation September 2011 to December 2011. There are two indicators namely observed values and simulated values each two models from surveyed data cross section and SRTM extracted data cross sections. The observed values consist of discharge and water level. [10].

The modeling of 2D hydrodynamic is supported by the topographic data with the high resolution, but now it is very difficult to obtain detailed supporting data for modeling. As a solution we used a Digital Elevation Model (DEM) which was generated from the ASTER data [11].

The RMSE index (Root Mean Squared Error) and the Nash Index are two criteria for calibration of the simulated models. RMSE and Nash index is used to evaluation of hydrological models with observed data [12]. Two performance indicators are NI (Nash Sutcliffe Index or Nash Index) and RMSE (Root Mean Square Error), which is written in the form of partial differential equations as follows:

NI (Nash-Sutcliffe Index):

$$
N I=1-\frac{\sum_{i=1}^{n}\left(Q_{0}-Q_{m}\right)^{2}}{\sum_{i=1}^{n}\left(Q_{0}-\bar{Q}_{0}\right)^{2}}
$$

RMSE (Root Mean Square Error):

$$
R M S E=\sqrt{\frac{\sum_{i=1}^{n}\left(Q_{0}-Q_{m}\right)^{2}}{n}}
$$


Upper Citarum River length up to Nanjung (daily discharge station) which is surveyed cross sections length 31 kilometers. Survey was at intervals between points as far as 100 meters and cross sections data about 300 cross sections. Accuracy is expressed by the magnitude of the error. If getting close to the simulation results with cross sections extracted from SRTM with surveyed cross section, so the better method or process is used.

The important data required for HEC-Geo RAS is the TIN (terrain data) or DEM. land use information is needed to be additional data sets. Using data DEM for hydrology and hydraulic modeling usually involve some points: (1) preprocessing of data; (2) model execution; and (3) post-processing/ visualization of results [13].

The most important data to input in HEC-RAS are river data cross sections. The function of cross section cut lines extract the elevation data from TIN data to make ground profile across channel flow. The intersection of cut lines with other RAS layers such as centerline and flow path lines are used to compute HECRAS attributes such as bank stations (locations that separate main channel from the floodplain), downstream reach lengths (distance between cross sections) and Manning n. Hence, creating of data cross sections to create good representation of channel bed and floodplain is important. The best guidelines must be followed in creating cross sections cut lines: (1) the digitized process are perpendicular to the direction of river flow; (2) in flood extent must span to over the all section that can be modeled; and (3) the digitized process are from left to right (looking downstream). Even though it is not needed, but it is a good method to keep spacing between data cross-sections more consistent [14]. The cross sections extracted from SRTM can be seen in Figure 2.

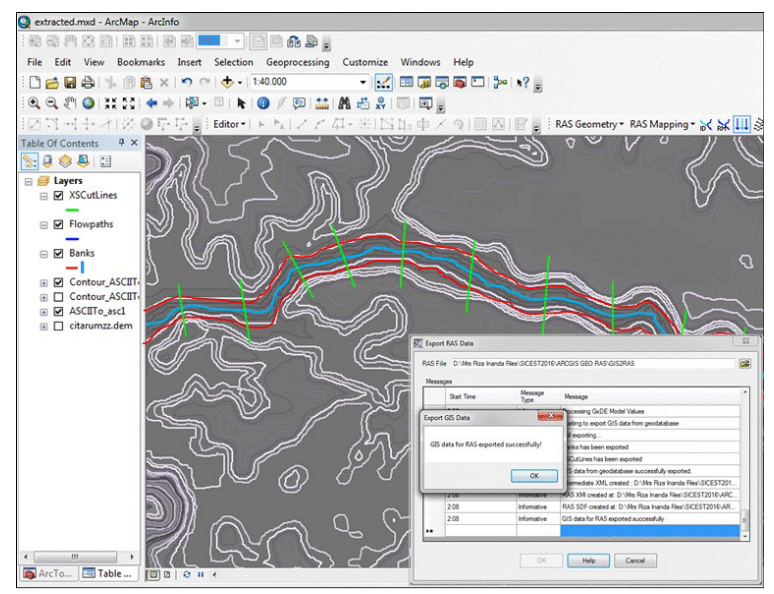

Fig.2. Upper Citarum River cross sections extracted from SRTM

Figure 2 shows that cross sections extracted from SRTM. The SRTM extracted river data cross sections could be used in hydraulic models to simulate stage and discharge hydrographs with considerable accuracy under the scarcity of measured cross sections data [15]. The geographic coordinate system of the DEM was converted to a projected coordinate system using the software package ArcGIS 10. The river branch was digitized along the center of the left and right bank. The cross-sections were automatically extracted along the river branch from the DEM data using the software HEC-Geo RAS [16].

\section{Results and discussions}

Two criteria are compared between observed discharge and simulated discharge with river surveyed data cross sections for period of calibration January 2011 to April 2011 in Nanjung. The validation period is from September 2011 to December 2011. Index of Performance indicator for calibration with NI (NashSutcliffe Index) is 0.81 and RMSE index (Root Mean Square Error) is 0.96. Index of Performance indicator for validation with Nash-Sutcliffe Index (NI) is 0.7 and Root Mean Square Error (RMSE) is 1.72. Nash Index range from $-\infty$ to 1 , the model which perfect data cross section with the observed data has Nash index NI=1. The model predictions are as accurate as the mean of the observed data has Nash Index $\mathrm{NI}=0$. If predictor better than model have Nash Index less than zero. RMSE index (Root Mean Square Error) is index used to gauge of the differences between values (sample and population values) predicted by a model or an estimator and the values observed. The calibration and validation can be seen in Figure 3.
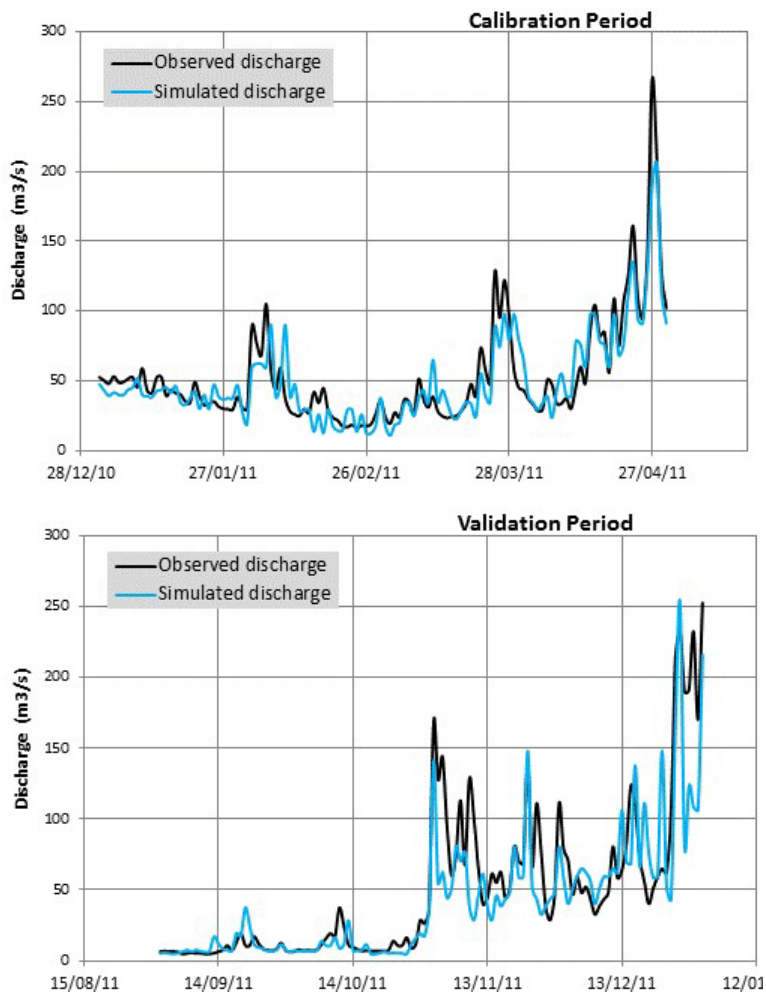

Fig.3. Calibration period and validation period

Figure 3 shows that discharge calibration discharges is simulated with period January to April and validation 
discharges is simulated with period September to December. It is simulation same with calibration period.

The comparison between simulated discharges and water depth models by surveyed data cross sections and SRTM cross sections can be seen in Figure 4.
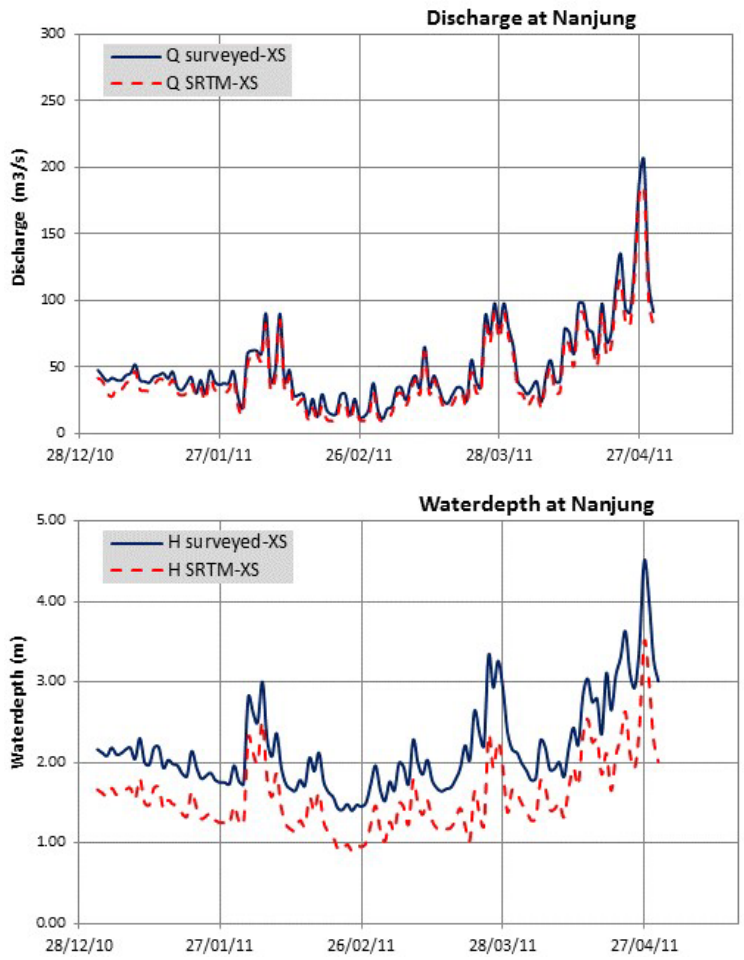

Fig.4. Simulated discharge between surveyed and SRTM; water depth between surveyed and SRTM

Fig. 4 shows that the result of discharges with simulation between surveyed and SRTM has small difference or almost the same and the result of simulated of water depth between surveyed and SRTM has a large difference. It is caused the difference of elevation cross sections surveyed-XS with the results generated SRTMXS using HEC-Geo RAS and ArcGIS.

Index of Performance indicator for comparison of simulated discharges between models by surveyed cross sections and SRTM cross sections at Nanjung with NI (Nash-Sutcliffe Index) is 0.95 and RMSE index (Root Mean Square Error) is 0.41 , it means discharge of simulated from model with extracted data cross sections SRTM is as good as from model with surveyed data cross sections. Index of Performance indicator for comparison of water depth between models by surveyed data cross sections and SRTM data cross sections at Nanjung with Nash-Sutcliffe Index (NI) is -0.21 and RMSE (Root Mean Square Error) is 0.04, it means simulated water depth from model with SRTM-extracted cross sections and from model built with surveyed cross sections are not good results. It occur because of low resolution and inadequate vertical accuracy of global data to cut lines data cross-section.

\section{Conclusions}

Based on the analysis that the output applied for Upper Citarum River show that SRTM data can be an alternative data to extract cross sections for Upper Citarum River modeling. Simulated daily discharge from model built with SRTM-extracted cross sections is as good as that of from model with surveyed cross sections. The comparison of simulated discharges between models by surveyed data cross sections and SRTM data cross sections have index of performance indicator for NI (Nash-Sutcliffe Index) is 0.95 and RMSE (Root Mean Square Error) is 0.41 . Index of Performance indicator for comparison of simulated discharges between models by surveyed cross sections and SRTM cross sections at Nanjung with NI (Nash-Sutcliffe Index) is 0.95 and RMSE (Root Mean Square Error) is 0.41.

The authors gratefully acknowledge that the research is supported by University of North Sumatera, Indonesia.

\section{References}

1. V T Chow, Open Channel Hydraulics, McGrawHill Book Company Inc., Kogakusha Company, LTD., Tokyo, Japan, (1959)

2. P Ricardo, J Karsten, Tampa, Florida, (2007)

3. Sanders, F Brett., Elsevier, 30, 1831-1843 (2007)

4. Gichamo, T.Z., Popescu, Jonoski, Solomatine, Elsevier, 31, 37-46 (2011)

5. $\mathrm{ADB}$ and Bappenas, Integrated Citarum Water Resources Management (ICWRM), Bandung, 2012.

6. N Kolecka, J Kozak, Pure and Applied Geophysics, Krakow, Poland, 171, (2014)

7. ESRI, Environmental Systems Research Institute, USA.

8. US ARMY Corps of Engineers, US Army Corps of Engineer, Washington, (2010)

9. US ARMY Corps of Engineers, US Army Corps of Engineer, Davis, (2009)

10. Chidungdoan, Anhtuandao, S Liong, R Sanders, J Liu, and T Fewtrell, 10th International Conference on Hydroinformatics, Hamburg, Germany, (2012)

11. Tarekegn, Tesfaye, Alemseged, Tom, Reggiani, Dinand, Elsevier, 12, 457-465 (2010)

12. V G Hoshin, K Harald, K. Y Koray, and F M Guillermo, Elsevier, 377, 80-91, (2009)

13. M Venkatesh, Tutorial on Using HEC-Geo RAS with Arc GIS 10 and HEC-RAS Modeling, School of Civil Engineering, Purdue University, (2012)

14. L Arturo, School of Civil and Construction Engineering, Oregon State University, (2013)

15. Niranjan, Pramanik., Rabindra, Dhrubajyoti, One Dimensional Hydrodynamic Modeling of River Flow Using DEM Extracted River Cross-Sections, (2010)

16. Amir, Khan, Rasul, Sharma, and Akram, $19^{\text {th }}$ Australasian Fluid Mechanics Conference, Melbourne, Australia, (2014) 